\title{
Multifractal analysis of earthquakes in Kumaun Himalaya and its surrounding region
}

\author{
P N S RoY* and S K MONDAL \\ Department of Applied Geophysics, Indian School of Mines, Dhanbad 826 004, Jharkhand, India. \\ *Corresponding author.e-mail: pns_may1@yahoo.com
}

Himalayan seismicity is related to continuing northward convergence of Indian plate against Eurasian plate. Earthquakes in this region are mainly caused due to release of elastic strain energy. The Himalayan region can be attributed to highly complex geodynamic process and therefore is best suited for multifractal seismicity analysis. Fractal analysis of earthquakes (mb $\geq 3.5$ ) occurred during 1973-2008 led to the detection of a clustering pattern in the narrow time span. This clustering was identified in three windows of 50 events each having low spatial correlation fractal dimension $\left(D_{C}\right)$ value $0.836,0.946$ and 0.285 which were mainly during the span of 1998 to 2005 . This clustering may be considered as an indication of a highly stressed region. The Guttenberg Richter b-value was determined for the same subsets considered for the $D_{C}$ estimation. Based on the fractal clustering pattern of events, we conclude that the clustered events are indicative of a highly stressed region of weak zone from where the rupture propagation eventually may nucleate as a strong earthquake. Multifractal analysis gave some understanding of the heterogeneity of fractal structure of the seismicity and existence of complex interconnected structure of the Himalayan thrust systems. The present analysis indicates an impending strong earthquake, which might help in better hazard mitigation for the Kumaun Himalaya and its surrounding region.

\section{Introduction}

The high level of seismicity is associated with Himalaya tectonic province and the bordering Ganga alluvial plain to the south. Possibility of large earthquakes of magnitude $>8$ due to the MHT (Main Himalayan Thrust) has been reported by several researchers (Khattri and Tyagi 1983a; Khattri 1987) on the basis of seismological evidence, where they mainly confirmed the existence of three seismicity gaps in the Himalayan plate boundary. Among the three seismicity gaps, the extent of the central gap lying between the rupture zones of the 1905 and 1934 earthquakes is very long and has the potential for sustaining two future great earthquakes. Further seismic cycle evidenced by numerous studies (Molnar 1987; Bilham et al. 1995; Gahalaut and Chander 1997) underlines the existence of a major seismic gap in western Nepal and surrounding region between the 1905 Kangra and the 1934 Bihar-Nepal earthquake areas. However, another major earthquake is yet to be recorded in this area over the past three centuries, and possibly since the 1255 event, which might be the last major rupture in this part of Nepal (Wright 1877; Bilham et al. 1995). The 1934 Bihar-Nepal earthquake, that ruptured a $100-300 \mathrm{~km}$ long part of the Himalayan arc (Molnar and Pandey 1989), seems to be the recurrence of some of these events (Bilham et al. 1995), whereas the 1803, 1833 and

Keywords. Fractal; multifractal; geodynamics; seismicity and earthquake stress pattern. 
1866 events could be related to the rupturing of a segment west of Kathmandu in central Nepal (Bilham 1995). A 500-800 km seismic gap which lies between $77^{\circ}$ and $84^{\circ} \mathrm{E}$ is yet to experience a great earthquake for more than two centuries (based on reliable British historical seismicity) and perhaps since the huge 1255 earthquake (Jouanne et al. 2004). Bilham et al. (1995) have hypothesized that, based on the assumption of constant convergence rate of $20 \mathrm{~mm} \mathrm{yr}^{-1}$ maximum slip deficit in the seismic gap may be around $15 \mathrm{~m}$, which may cause one or several magnitude $>8$ earthquake.

The need for meticulous scientific efforts for the mitigation of earthquake hazard in earthquake prone areas is very much in need. Recent advances in the understanding of physical processes leading up to the catastrophic occurrences of earthquake, permits the assessment of seismic hazard in seismically prone areas to a useful level of accuracy. The spatial multifractal dimension $\left(D_{q}\right)$ provides a quantitative measure of the spatial clustering and hence the crustal deformation in space and time of a region (Aki 1981, 1984; King 1983; Main 1996; Nakaya and Hashimoto 2002; Öncel and Wilson 2006; Roy and Nath 2007). The physical laws underlying the multifractal structures are scale-invariant in nature. The occurrence of earthquakes is causally related to fractures that have multifractal structure in their space, time and magnitude distributions.

The sections of the plate boundary that have not ruptured are indicated as seismic gaps. The west of 1905 Kangra earthquake (the Kashmir gap) ruptured by recent October 8, 2005 earthquake of $M_{w}=7.7$; and the section between the 1905 Kangra and the 1934 Bihar earthquakes (the central gap) are yet to be ruptured and are identified as locals which may have high potential for future great earthquakes as proposed by Khattri (1987).

The great earthquakes are associated with the ridges (Khattri 1987). This may be interpreted in terms of an asperity model (Beck and Ruff 1984; Rundle et al. 1984) which proposes that the ridges are locales of stress concentration. It also seems that the faulting terminates in regions of the depressions having soft rocks which flank the ridges. The ridges are part of the system of NEtrending fault and structural elements that characterize the Indian shield on the southern margin of the Sindhu-Ganga depression. As mentioned earlier these transverse tectonic elements have also been traced into Himalaya (Valdiya 1976; Khattri and Tyagi 1983b). The nature of the foredeep side of the Himalaya in respect of relative thickness of sediments (i.e., the depth of the basement) has been given by Khattri (1987). The western sector constituting the Punjab shelf is a region where basement rocks occur at relatively shallow depths. This shelf is characterized on the east by the NE-trending Delhi-Hardwar ridge which is an old tectonic feature of Archean age.

Recent displacement field study in Himalayas is satisfactorily simulated by a dual-dislocation elastic model involving thrust and strike-slip components. The thrust component is $19 \mathrm{~mm} \mathrm{yr}^{-1}$ and the dextral strike-slip component is $1-2 \mathrm{~mm} \mathrm{yr}^{-1}$. There has been misfit between the present-day displacement field above the locked zones and the dislocation model which nevertheless is not significant, suggesting that the aseismic component along the external zone of the MHT seems to be negligible. Six years study of Jouanne et al. (2004) has shown that some current deformation that occurs in the outer belt may affect the restricted zones of the detachment. The agreement of the longterm contraction rates across the frontal part of the Himalayas and the aseismic slip rate simulated below the Higher Himalayas suggests that most of the slip in the outer belt occurs through earthquakes, and also supports the hypothesis of a serious slip deficit in western Nepal. The twodislocation model suggests that the width of the locked zone between the MFT and the creeping zone is not of the same order, but rather greater, in western Nepal than in central Nepal. Jouanne et al. (2004) have identified that the width of the locked zone gives an upper bound for the width of the rupture, and suggested that earthquakes as great as, or greater than, those that affected central-eastern Nepal (i.e., $\geq 8.4 \mathrm{M}$ from the 1934 Bihar earthquake) could affect western Nepal, which is also emphasized by the present multifractal analysis of stress pattern of earthquakes.

In the present study, correlation integral method (Grassberger and Procaccia 1983; Roy and Ram 2006; Roy and Padhi 2007) is exercised on a catalogue of earthquakes to determine correlationdimension and multifractal dimension or generalized fractal dimension. Initially an analysis of temporal variations of fractal dimension $\left(D_{C}\right)$, were carried out by considering 50 events consecutive windows of the Kumaun Himalaya and its surrounding region within the entire study area (latitude $28^{\circ}-33^{\circ} \mathrm{N}$ and longitude $76^{\circ}-82^{\circ} \mathrm{E}$, figure 1 , Gansser 1964). Spatio-temporal study of the events led us to detect significant drop in $D_{C}$ values with respect to time indicative of a definite pattern of earthquakes clustering. The study was also repeated for 100 event windows and higher number of subsets in order to confirm statistical robustness of results. The analysis of multifractal dimension of seismicity further confirmed the existence of heterogeneous fractal nature which is an indication of complex stress pattern of the region (Legrand et al. 1996; Öncel and Wilson 2004). In order to have a holistic view of the stress pattern, the Guttenberg 


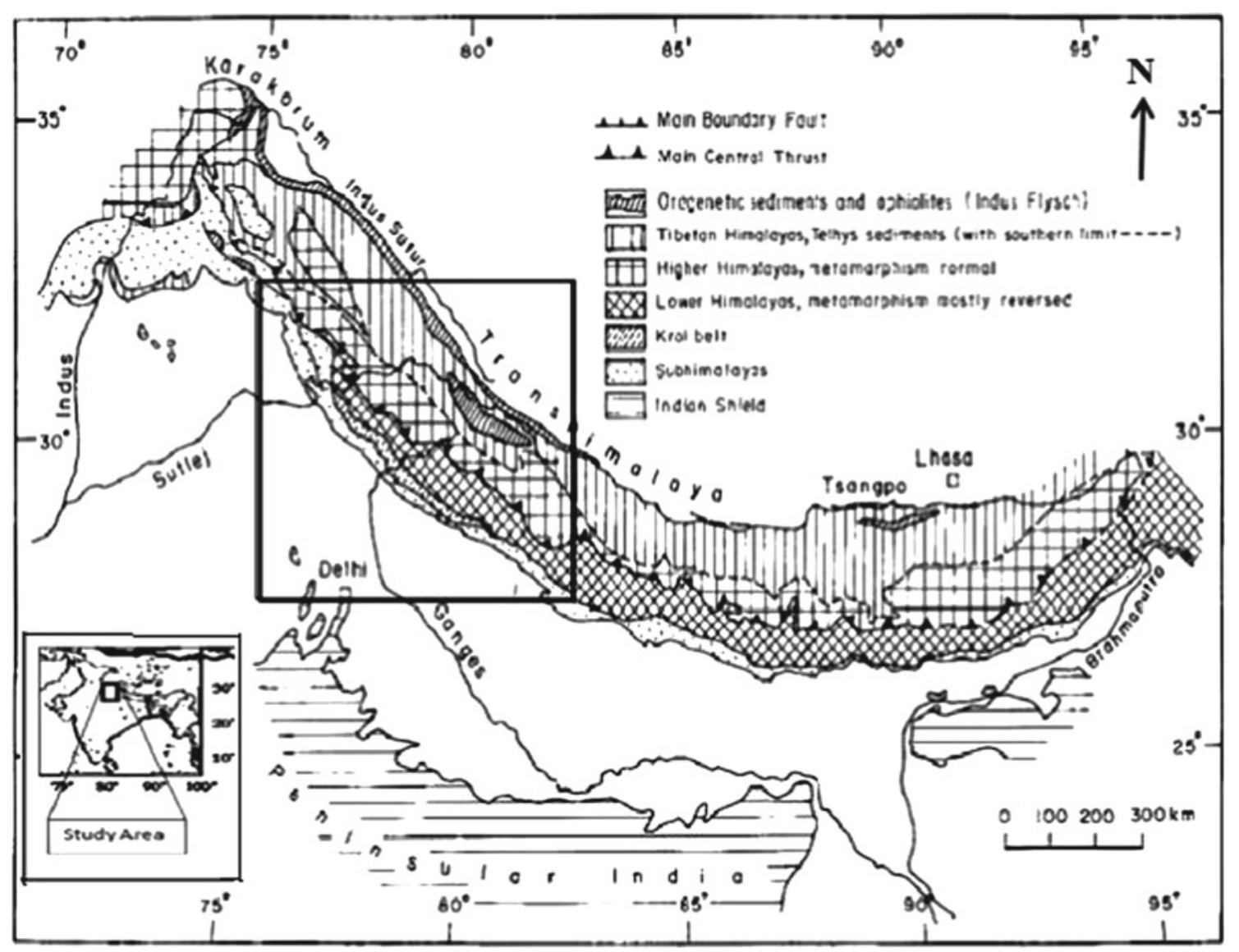

Figure 1. Tectonic map of the Himalaya and adjoining regions showing the major fault zones, and lithotectonic provinces where the area of study denoted by a box (after Gansser 1964).

Richter b-values are also determined for the same subsets considered for the determination of spatiotemporal variation of seismicity. Finally, the seismicity pattern of clustering may be used for identifying highly stressed regions. These patterns of clustering and low $D_{C}$ value patches were used for developing a possible model explaining the state prior to impending strong earthquakes.

\section{Methods}

In the present study, correlation integral method (Grassberger and Procaccia 1983) is exercised on a catalogue of earthquakes to determine correlationdimension. A 'unique finger print' of a multifractal object requires the introduction of an infinite hierarchy of fractal dimensions, known as generalized fractal dimensions as given below:

$$
D_{q}=\left\{\frac{1}{q-1}\right\} \operatorname{Lim}_{r \rightarrow 0}\left[\log _{10} \frac{\left(\sum_{i}\left\{P_{i}(r)\right\}^{q}\right)}{\log r}\right]
$$

where $D_{q}$ exhibits a non-trivial scaling behaviour for different values of $q=1,2,3, \ldots, P_{i}(r)$ is the probability that the events fall into a square box of length $r$. The generalized dimension $D_{q}$ is defined for all real $q$ and is a monotonically decreasing function of $q$. There are a lower and an upper limiting dimension $D_{-\infty}$ and $D_{\infty}$ respectively, which are related to the regions of the set, in which the measure is 'most dilute' and 'most dense' respectively. This phenomenon was described for the first time by Mandelbrot (1989) in the context of fully developed turbulence. Today, it is known as multifractality. The question about the processes that create multifractal structures is important. Usually multiplicative cascades of random processes generate multifractal structures, while additive processes produce simple fractals (monofractals) (Bunde et al. 1990).

Using equation (1), one readily finds fractal dimensions for integer $q$ as special cases. The correlation-dimension are obtained from

$$
\text { CorrelationDimension }=\underset{q \rightarrow 2}{\operatorname{Lim} D_{q}}=D_{2}=D_{C} .
$$

In two dimensions, values of $D_{q}$ approaching a value of 2 signify a uniform coverage of the plane. 
In this paper, the spherical triangle method has been used to determine the distance between two epicentres (Teotia et al. 1997; Öncel and Wilson 2002; Mandal et al. 2005).

\subsection{Correlation dimension}

The fractal correlation dimension is derived from the correlation integral (Grassberger and Procaccia 1983; Hilarov 1998; Roy and Ram 2006) which is a cumulative correlation function that measures the fraction of points in the 2-dimensional space $r$, a sequential distance and is defined as:

$$
C(r)=\frac{2}{N(N-1)} \sum_{j=1}^{N} \sum_{i=j+1}^{N} H\left(r-r_{i j}\right)
$$

where $N$ (for 50 events window, $N$ will be ${ }^{50} C_{2}$, i.e., 1225 and for 100 events window $N$ will be 4950) is the total number of pairs in the fractal set to determine $D_{C}, r_{i j}$ is the distances between the points of a set, obtained through spherical triangle method and, $H$ is the Heaviside step function. $C(r)$ is seen to be proportional to the number of pairs of points of the fractal set separated by a distance less than $r$. In the graph of $C(r)$ in logarithmic coordinates a linear part for middle $r$-values with slope $D_{C}$ is computed to be the fractal dimension of the system. The graph $\log C(r)$ versus $\log r$ at different stages of the fracture process is shown in figure 2 .

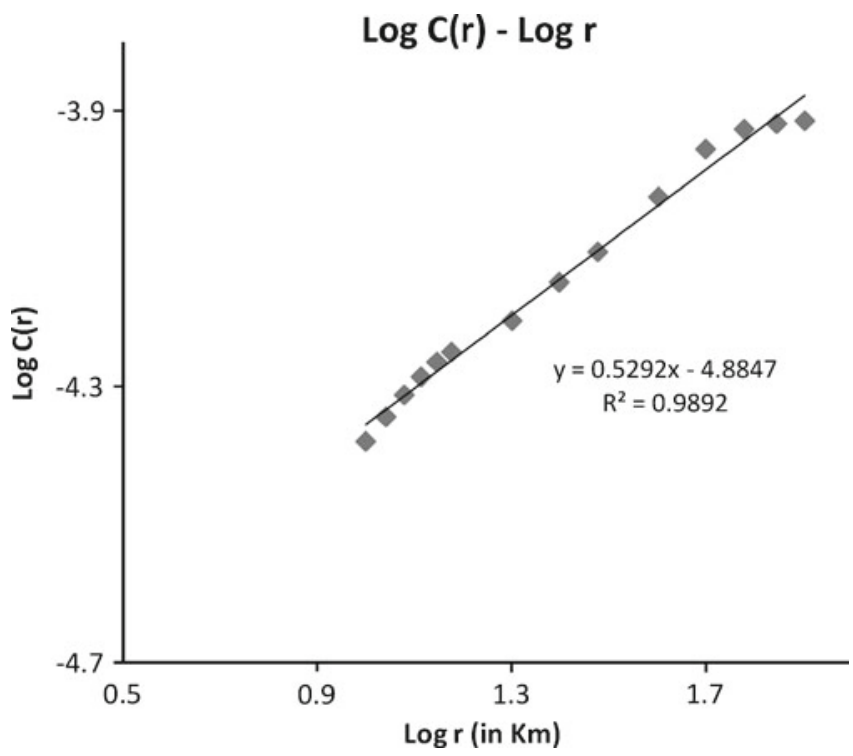

Figure 2. $\log C(r)$ versus $\log r$ is shown for determination of lowest $D_{C}$ (tenth time window) from the slope of 100 events window earthquake distributed within the latitude $\left(28^{\circ}-33^{\circ} \mathrm{N}\right)$ and longitude $\left(76^{\circ}-82^{\circ} \mathrm{E}\right) . R^{2}$ represents correlation coefficient of the regression line.
The curves show a clear self-similar behaviour in a wide range of about two orders of magnitude on the space scale. Deviations from linear dependence in the range of large scales are connected with the finite size of samples, while the other deviation in the range of small scales reflects the boundary effect of data for the region of investigation.

\subsection{Generalized dimension}

The multifractal dimension $D_{q}$ is a parameter representing the complicated fractal structure or multi-scaling nature. The general methods of calculating $D_{q}$ are the fixed-mass method, the fixed-radius method and the box-counting method (Grassberger and Procaccia 1983; Halsey et al. 1986; Mandelbrot 1989). In the present case, the extended Grassberger-Procaccia method has been used, which can recover the dimension from a time series (Grassberger and Procaccia 1983; Pawelzik and Schuster 1987). The related formula are given below:

$$
\begin{aligned}
\log C_{q}(r)=D_{q} \log r(r \rightarrow 0) \\
C_{q}(r)=\left\{\frac{1}{N} \sum_{j=1}^{N}\right. \\
\left.\times\left[\frac{1}{N} \sum_{i=j}^{N} H\left(r-\left|X_{i}-X_{j}\right|\right)\right]^{q-1}\right\}
\end{aligned}
$$

where $C_{q}(r)$ is the $q$ th order correlation integral. The above formulation has been used for developing MATLAB code in order to process the datasets. $D_{q}$ is the slope of the linear segment (i.e., scaling region) for the graph of $\log r-\log C_{q}(r)$. Many $D_{q}$ values can be calculated using the above method for various $q$ values. The curve of $q-D_{q}$ is called the $D_{q}$ spectrum.

The generalized dimension $D_{q}$ was calculated for consecutive 50 events time windows, to see the temporal variation of $D_{q}$.

\section{Data}

The USGS PDE data $(\mathrm{mb} \geq 3.5)$ has been used for the period 1973-2008 which also includes Wadia Institute of Himalayan Geology data $(\mathrm{mb} \geq 1.2)$ for the period of 2004 to 2006 . The latter was obtained from a study of Kumaun Himalayan region in search of typical patterns of earthquake using the quantitative values of fractal correlation dimension of the region. Figure 3(a) shows the earthquakes magnitude versus time for the entire study 

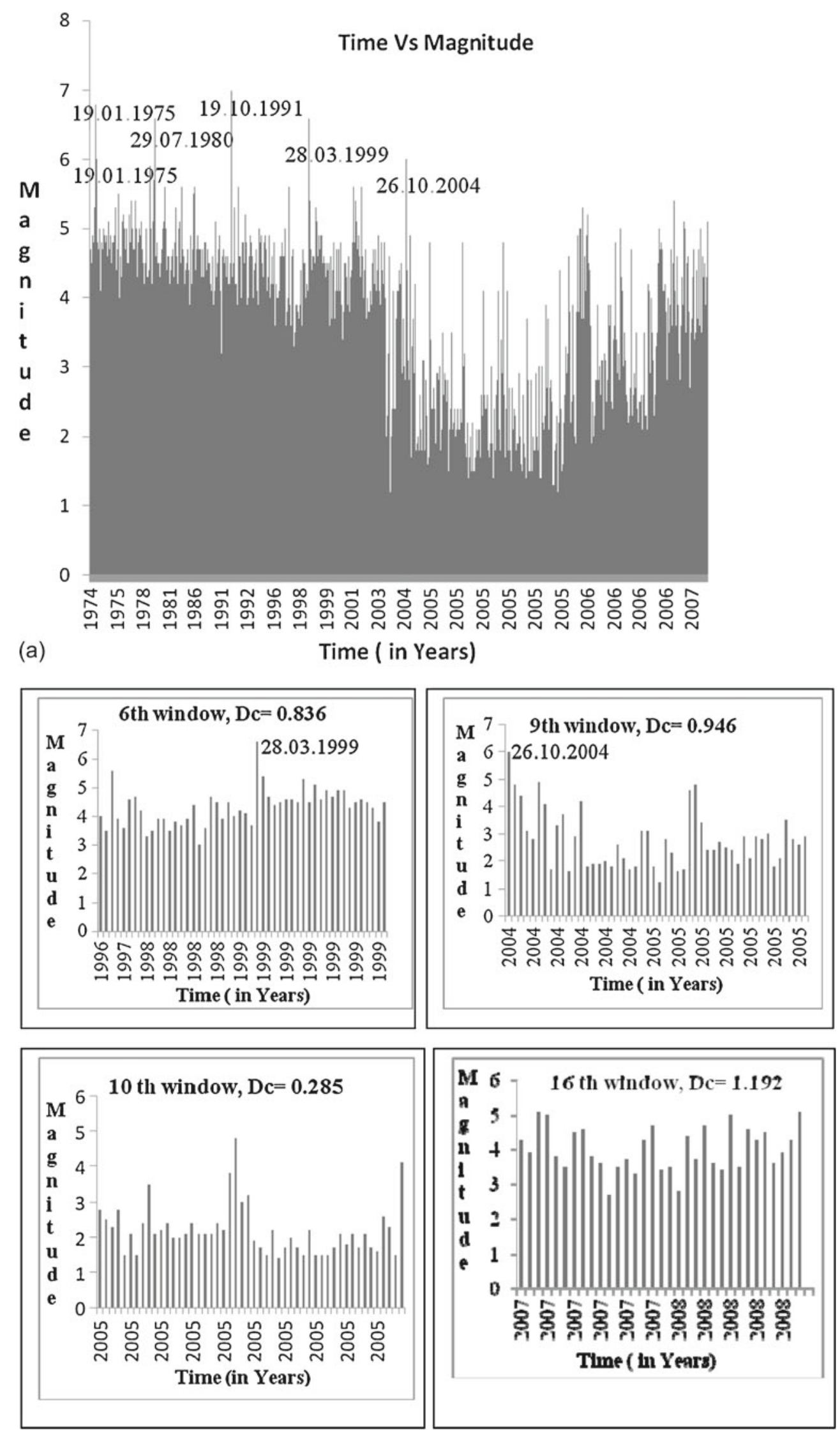

(b)

Figure 3. (a) The plot for the earthquakes magnitude versus time for the entire study area, is shown. The date indicated in the graph show earthquakes of magnitude $6 \mathrm{M}$ and above for the entire study area. (b) The plots for earthquake magnitude versus time for four low $D_{C}$ windows, 6 th, 9 th, 10 th and the last 16 th window. 
Table 1. Comparative variation of consecutive 50 event windows for $D_{C}$ and $D_{2}-D_{22}$ values for the entire study region.

\begin{tabular}{|c|c|c|c|}
\hline $\begin{array}{l}\text { Serial } \\
\text { no. }\end{array}$ & $\begin{array}{l}\text { Mean time (t) of each } 50 \text { event } \\
\text { window (in months/remarks) }\end{array}$ & $D_{C}$ & $\begin{array}{c}D_{2}-D_{22} \\
\text { value }\end{array}$ \\
\hline 1 & 26.11 & 1.615 & 1.543 \\
\hline 2 & 72.74 & 1.522 & 1.450 \\
\hline 3 & 148.44 & 1.824 & 1.738 \\
\hline 4 & 214.58 & 1.431 & 1.363 \\
\hline 5 & 264.77 & 1.546 & 1.473 \\
\hline 6 & 308.21 (6.6Ms, 28.03.99) & 0.836 & 0.796 \\
\hline 7 & 342.25 & 1.295 & 1.234 \\
\hline 8 & 372.28 & 1.280 & 1.217 \\
\hline 9 & $389.029\left(\right.$ Low $\left.D_{c}, 28.12 .04\right)$ & 0.946 & 0.904 \\
\hline 10 & 391.29 (Low $\left.D_{c}, 01.03 .05\right)$ & 0.285 & 0.272 \\
\hline 11 & 392.73 & 1.346 & 1.282 \\
\hline 12 & 395.54 & 1.253 & 1.192 \\
\hline 13 & 401.04 & 1.263 & 1.511 \\
\hline 14 & 405.98 & 1.579 & 1.392 \\
\hline 15 & 412.87 & 1.447 & 1.392 \\
\hline 16 & 426.47 & 1.192 & 1.129 \\
\hline
\end{tabular}

Table 2. Values of $D_{C}$ and $D_{2}-D_{22}$ versus time for consecutive 100 events windows in the study region.

\begin{tabular}{llccc}
\hline $\begin{array}{l}\text { Serial } \\
\text { no. }\end{array}$ & $\begin{array}{c}\text { Mean time } \\
\text { with date }\end{array}$ & $\begin{array}{c}\text { Duration of } \\
100 \text { events }\end{array}$ & $D_{C}$ value & $\begin{array}{c}D_{2}-D_{22} \\
\text { value }\end{array}$ \\
\hline 1 & $58.090(12.10 .77)$ & 16.12 .73 to 10.08 .81 & 1.468 & 1.399 \\
2 & $171.735(14.02 .87)$ & 10.09 .81 to 21.07 .92 & 1.661 & 1.583 \\
3 & $281.332(16.02 .96)$ & 26.07 .92 to 12.09 .99 & 1.252 & 1.19 \\
4 & $356.568(24.04 .02)$ & 08.11 .99 to 15.10 .04 & 1.363 & 1.297 \\
5 & $\mathbf{3 8 9 . 2 2 8 ( 0 2 . 0 1 . 0 5 )}$ & $\mathbf{2 6 . 1 0 . 0 4}$ to $\mathbf{0 7 . 0 3 . 0 5}$ & $\mathbf{0 . 5 2 9}$ & $\mathbf{0 . 5 0 4}$ \\
6 & $394.377(03.06 .05)$ & 09.03 .05 to 28.08 .05 & 1.371 & 1.305 \\
7 & $402.109(21.01 .06)$ & 28.08 .05 to 18.06 .06 & 1.417 & 1.336 \\
8 & $420.472(24.07 .07)$ & 19.06 .06 to 04.09 .08 & 1.506 & 1.443 \\
& & (with 83 events) & & \\
\hline
\end{tabular}

Table 3. Variation of consecutive 100 event windows fractal correlation dimension $\left(D_{C}\right)$ and $b$-value with time for the events in the entire study region.

\begin{tabular}{lllcr}
\hline $\begin{array}{l}\text { Serial } \\
\text { no. }\end{array}$ & \multicolumn{1}{c}{$\begin{array}{c}\text { Mean time } \\
\text { with date }\end{array}$} & $\begin{array}{c}\text { Duration of } \\
100 \text { events }\end{array}$ & $D_{C}$ value & b value \\
\hline 1 & $58.090(12.10 .77)$ & 16.12 .73 to 10.08 .81 & 1.468 & 0.7534 \\
2 & $171.735(14.02 .87)$ & 10.09 .81 to 21.07 .92 & 1.661 & 0.6201 \\
3 & $281.332(16.02 .96)$ & 26.07 .92 to 12.09 .99 & 1.252 & 0.6980 \\
4 & $356.568(24.04 .02)$ & 08.11 .99 to 15.10 .04 & 1.363 & 1.0557 \\
5 & $\mathbf{3 8 9 . 2 2 8 ( 0 2 . 0 1 . 0 5 )}$ & $\mathbf{2 6 . 1 0 . 0 4}$ to $\mathbf{0 7 . 0 3 . 0 5}$ & $\mathbf{0 . 5 2 9}$ & $\mathbf{0 . 4 0 0 5}$ \\
6 & $394.377(03.06 .05)$ & 09.03 .05 to 28.08 .05 & 1.371 & 0.5554 \\
7 & $402.109(21.01 .06)$ & 28.08 .05 to 18.06 .06 & 1.417 & 0.4024 \\
8 & $420.472(24.07 .07)$ & 19.06 .06 to 04.09 .08 & 1.506 & 0.4399 \\
& & (with 83 events) & & \\
\hline
\end{tabular}

area. The consecutive 16 windows formed for each 50 events period totaling to 783 earthquakes in the study region is shown in table 1 . The analysis is also repeated by forming consecutive eight windows for 100 event periods in the entire study area and is shown in table 2. The main reason behind reanalyzing with bigger size temporal window is to focus on statistical robustness. 
The known historical seismicity formed the basis of selecting our domain of analysis.

If the window sizes were taken to be 100 or 150 events which are usually done by many authors, we expect that the shorter patterns will be missed out and study will be less diagnostic. Nakaya and Hashimoto (2002) indicate that in order to detect a more sensitive temporal variation of multifractal dimension within shorter time spans it is necessary to analyse time events over a shorter time periods. If we take less than 50 events window it becomes difficult to obtain reliable linear ranges for middle $r$-values in the graphs of $\log r$ vs. $\log$ $C(r)$. The analysis was done for an active tectonic setting area in the study area to find the potential for future strong earthquake and is shown in tables 3 and 1 . The scaling range for the linear portion of $\log r$ versus $\log C(r)$ plot is about $5-90 \mathrm{~km}$, which is well within the region of the study considered. The value of scaling region is approximately smaller than $1 / 3-1 / 4$ of the side length of analysis region complying with the study (Hirata and Imoto 1991) ruling out boundary effect on our analysis.

\section{Results}

The initial study of correlation fractal dimension of all events occurring in the Kumaun Himalaya and its surrounding region during 1973 to 2008, shows that its values have fluctuating nature with time. The significant variation of $D_{C}$ value with time can be observed in figure 4 and is listed in table 1 . On the other hand, figure $5(\mathrm{a}$ and $\mathrm{b})$ depicts low $D_{C}$ patches and clustering of events which contributes to low $D_{C}$ patches. The $D_{C}$ values have been plotted against mean time of each 50 event windows for consecutive periods to study the variation of spatial correlation dimension with time. Here the low $D_{C}$ value patches indicate the intense clustering that is observed in figure $5(\mathrm{a}$ and $\mathrm{b})$. The $D_{C}$ contour in figure 5 (a) gives an idea about the possible patches of lowest $D_{C}$ values which may be considered to correspond to the highly stressed zones and from where strong earthquake ruptures may initiate in the future (Öncel et al. 1996; Roy and Padhi 2007; Roy and Mondal 2010).

\subsection{Analysis for fractal nature of the entire study area}

High clustering that leads to low $D_{C}$ (correlation fractal dimension) values (Telesca et al. 2001; Roy and Padhi 2007) was observed for a 50 events window with low $D_{C}$ values of 0.836 (for the window with mean time on 3.5.1998), 0.946 (for the window with mean time on 28.12.2004) and 0.285 (for the window with mean time on 1.3.2005) as indicated in figure 4 . The plots for earthquake magnitude versus time for three low $D_{C}$ windows, 6th, 9 th, 10th and the last 16th window is shown in figure 3(b). The study was also repeated for 100 events window in order to compare the performance with the study of 50 events. Figure 4 clearly indicates that the 100 events $D_{C}$ variation with time is not as sensitive as 50 events window, here

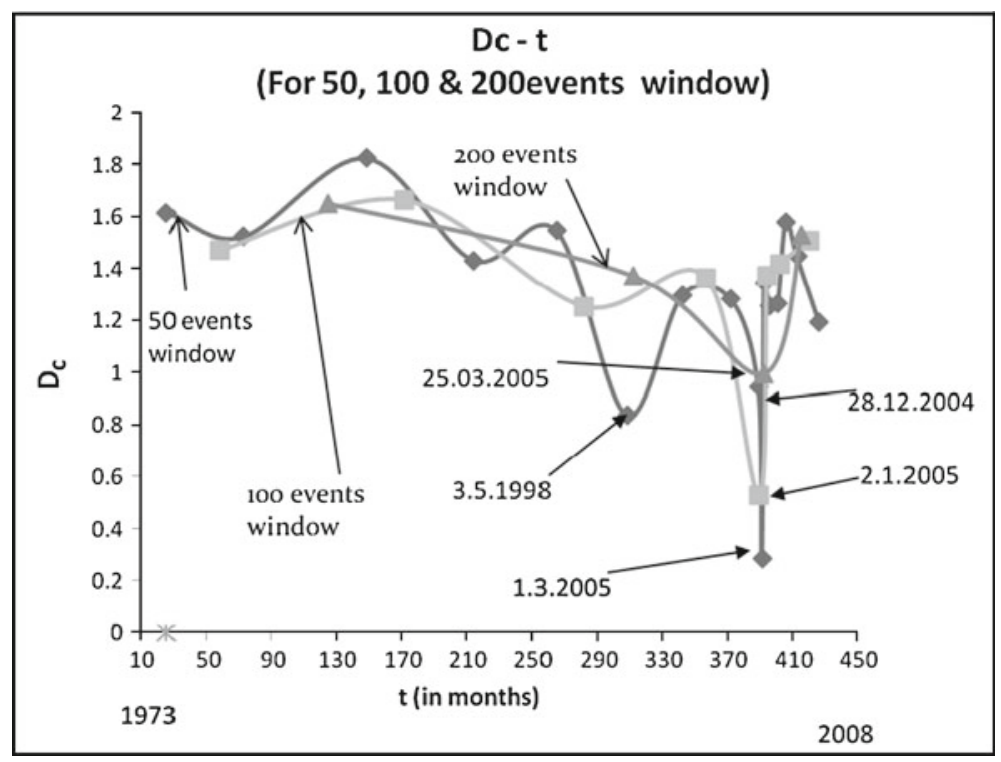

Figure 4. The comparative study of various consecutive subsets of 50 event windows, 100 event windows and 200 events is shown in order to see the sensitiveness of $D_{C}$ value. The lowest $D_{C}$ obtained for all the subsets during the year 2005 are consistent with each other. Here the temporal variation of $D_{C}$ is shown for 50 events where the mean time (3.5.1998), (28.12.2004) and (1.3.2005) represents low $D_{C}$ of $0.836,0.946$ and 0.285 , respectively. 

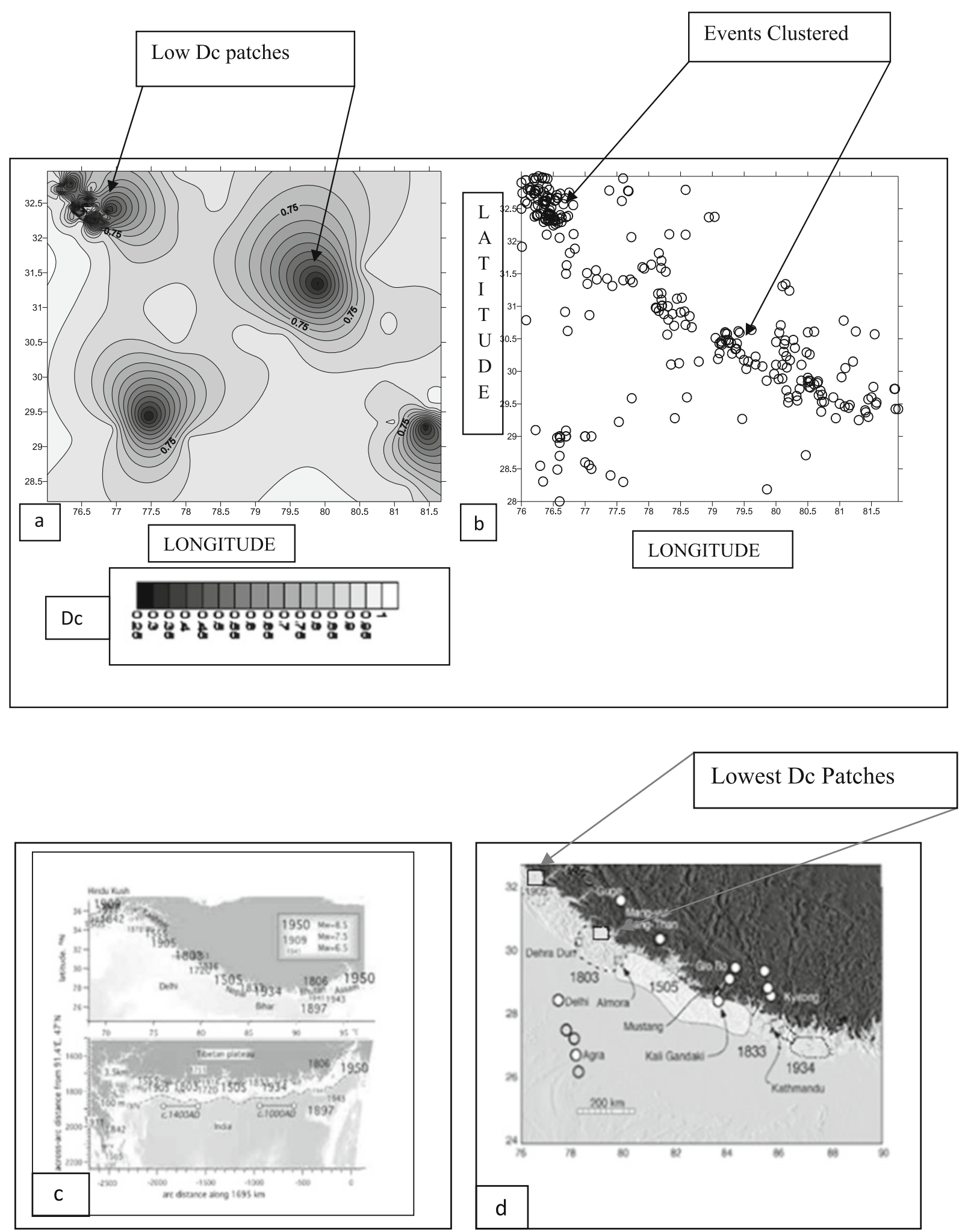

Figure 5. (a) $D_{C}$ value contour plotted for three windows of 50 events each with low $\mathrm{D}_{C}$ values 0.836 and 0.946 and 0.285 in the considered study region. The lowest $\mathrm{D}_{C}$ value patch represents the possible highly stressed region and significant clustering of events. (b) Spatial distribution of 150 events that contributed three low $D_{C}$ values and hence the remarkable low $D_{C}$ patches in the entire study area is shown in (a). (c) Significant earthquakes 1500-1950 plotted on a Cartesian projection (top) and on an oblique Mercator projection (below) centered on the pole (after Bilham and Ambraseys 2005). (d) Estimates for the rupture areas of earthquakes between 1500 and 1934 in the central Himalaya. The two boxes indicate the lowest $D_{C}$ patches in the study area (after Bilham and Ambraseys 2005). 


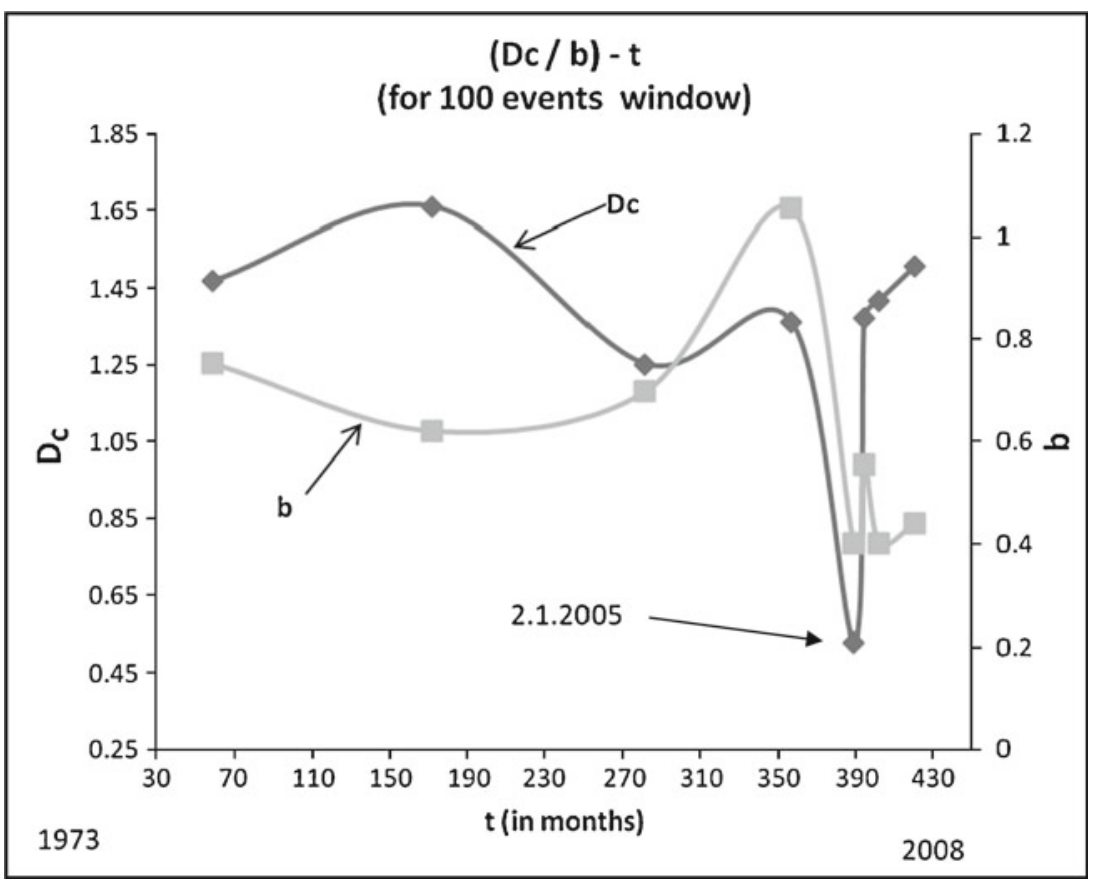

Figure 6. The temporal variation of $D_{C}$ and b-value for consecutive hundred events window is shown, where point given by box (2.1.2005) represents significant clustering of events with low $D_{C}$ value 0.529 and also low b-value 0.4 for the entire study area.

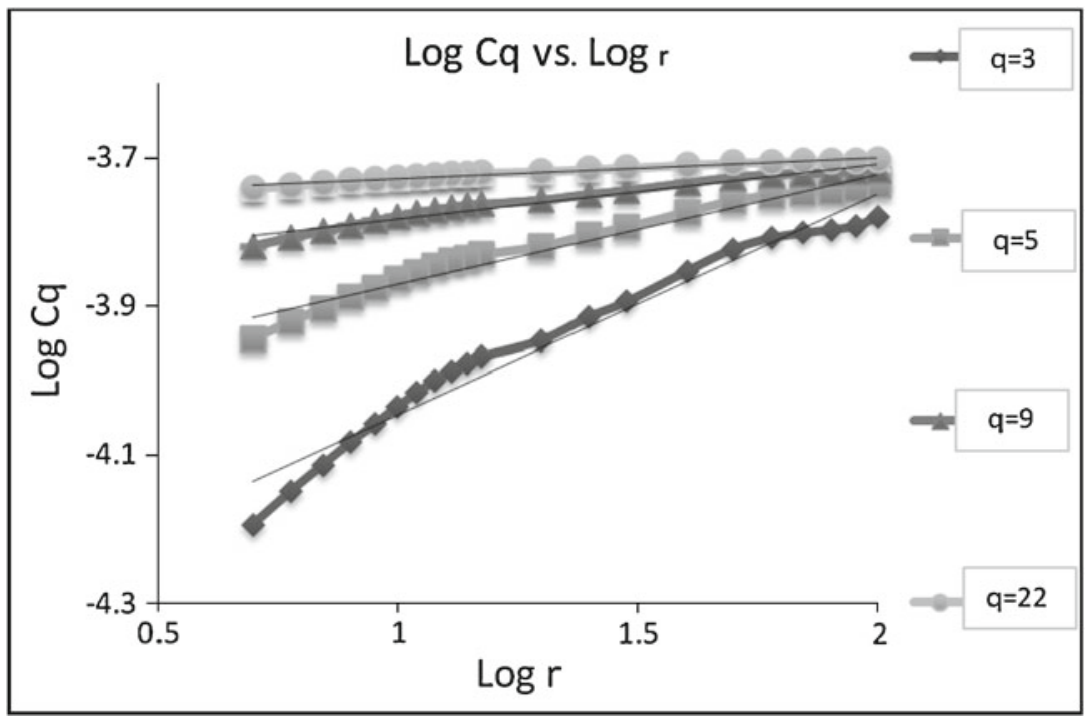

Figure 7. The $\log C_{q}(r)-\log r$ relationship is shown for spatial distribution of earthquakes for the 5th window of 100 events having lowest $D_{C}$ value of 0.529 in the study area. The slope of the linear portion of graph $\log C_{q}(r)-\log r$ gives $D_{q}$ for $q=3$ to 22 for the windows within the region of study.

clustering, i.e., low $D_{C}$ value of 0.529 was only obtained with the mean time 389.23 months (corresponding date 2.1.2005). Corresponding b-value plot in figure 6 depicts a positive correlation with the above $D_{C}$ value. Decrease of b-value (Sammonds et al. 1992; Xie 1992; Feng and Seto 1999) indicates the likelihood of strong earthquake, and the corresponding low $D_{C}$ value indicates increased shear strain. Thus the correlation of b-value and $D_{C}$ gives positive indication of impending strong earthquake. Figure 4 also gives comparative study of respective 50, 100 and 200 event windows with common low $D_{C}$ value for the year 2005 and the resolution for different size of windows are also visible. The comparative study illustrate that 50 event plots have better diagnostic feature, i.e., high resolution of $D_{C}$ value with time than the 200 event windows. 


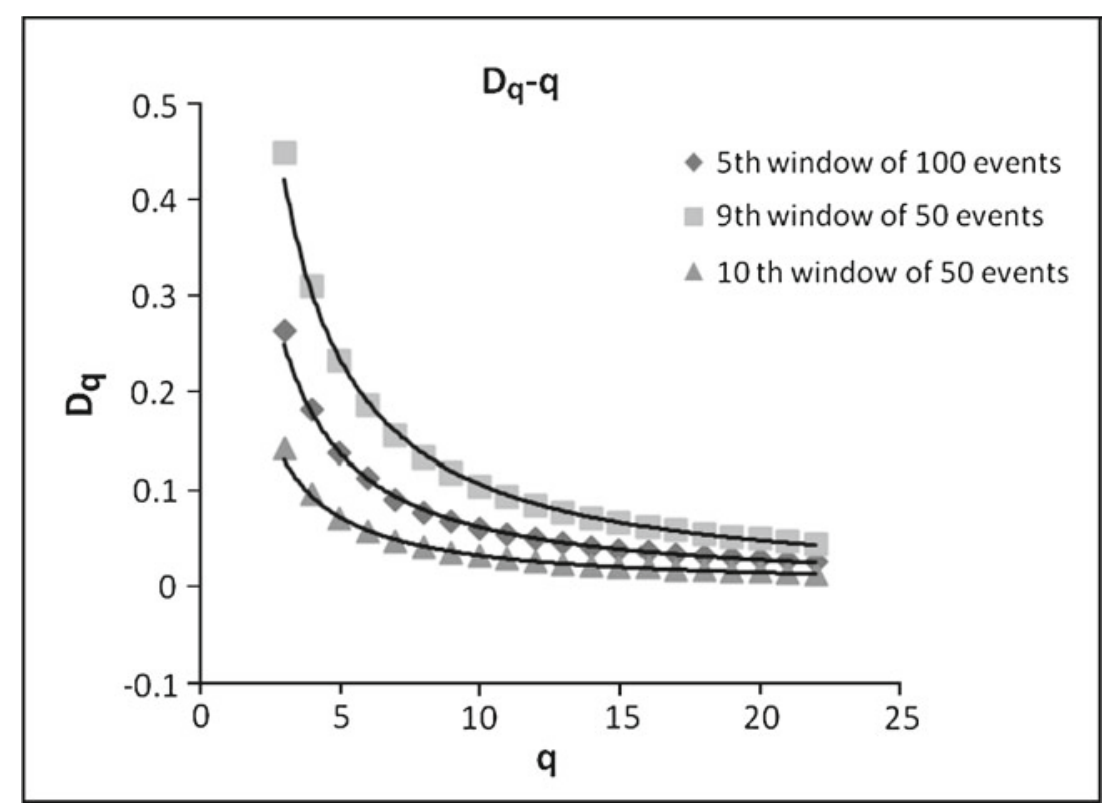

Figure 8. $D_{q}-q$ plot or $D_{q}$ spectrum is shown for the 5 th window of 100 events, 9 th and 10 th windows of 50 events (of lowest $D_{C}$ ) with $q=2$ to 22 . With the increase of $q$ value leads to exponential decay of $D_{q}$ value which shows the multifractal nature for the events occurrence within the region of study.

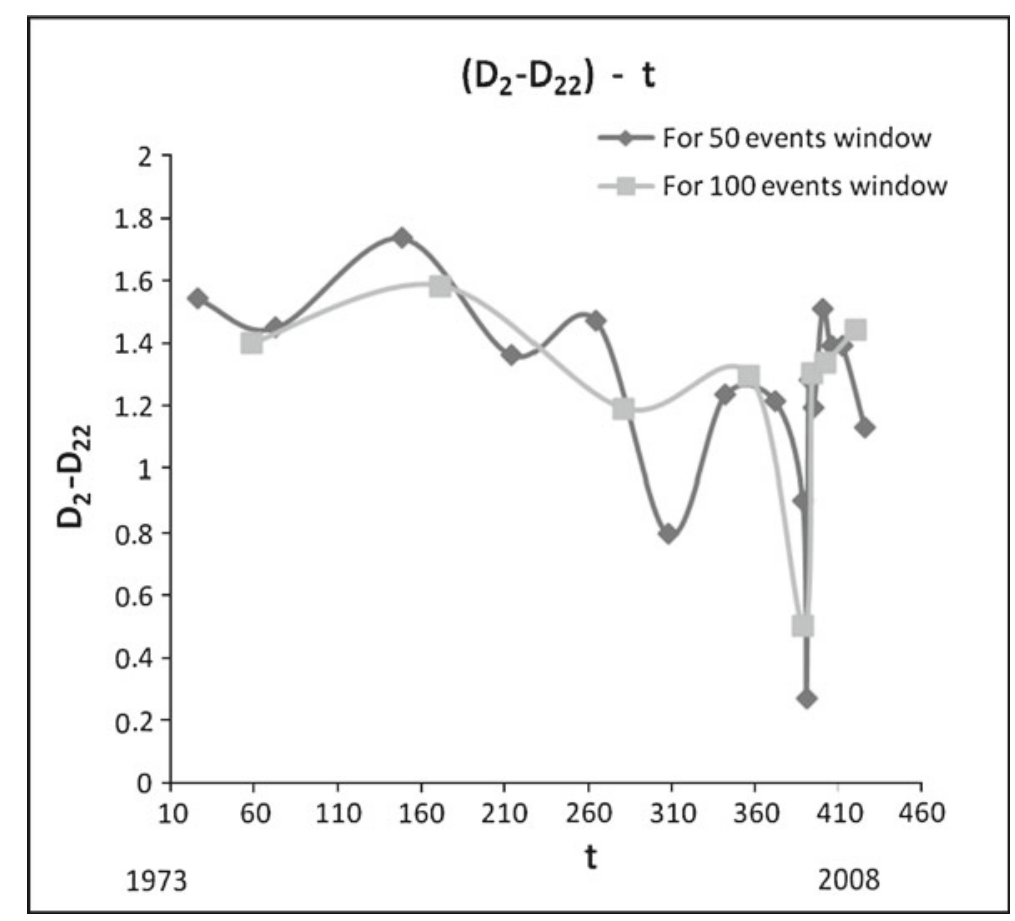

Figure 9. The plot illustrates temporal variation of the difference $D_{2}-D_{22}$ for spatial distribution of consecutive 50 events and 100 event windows within the study region.

\subsection{Analysis for multifractal nature of the entire study area}

Generalized fractal dimension: The slope for $\log C_{q}(r)-\log r$ is examined for the 100 event windows which contributed the lowest $D_{C}$ value as shown in figure 7. Similarly, it was done for the 50 events window. The range of $r$ for which a plot of $\log C_{q}(r)$ against $\log (r)$ is a straight line, is an indication of the range over which a fractal model holds. The $D_{q}$ can be obtained from the linear portion of the plot $\log C_{q}(r)-\log r$. Figure 8 depicts 


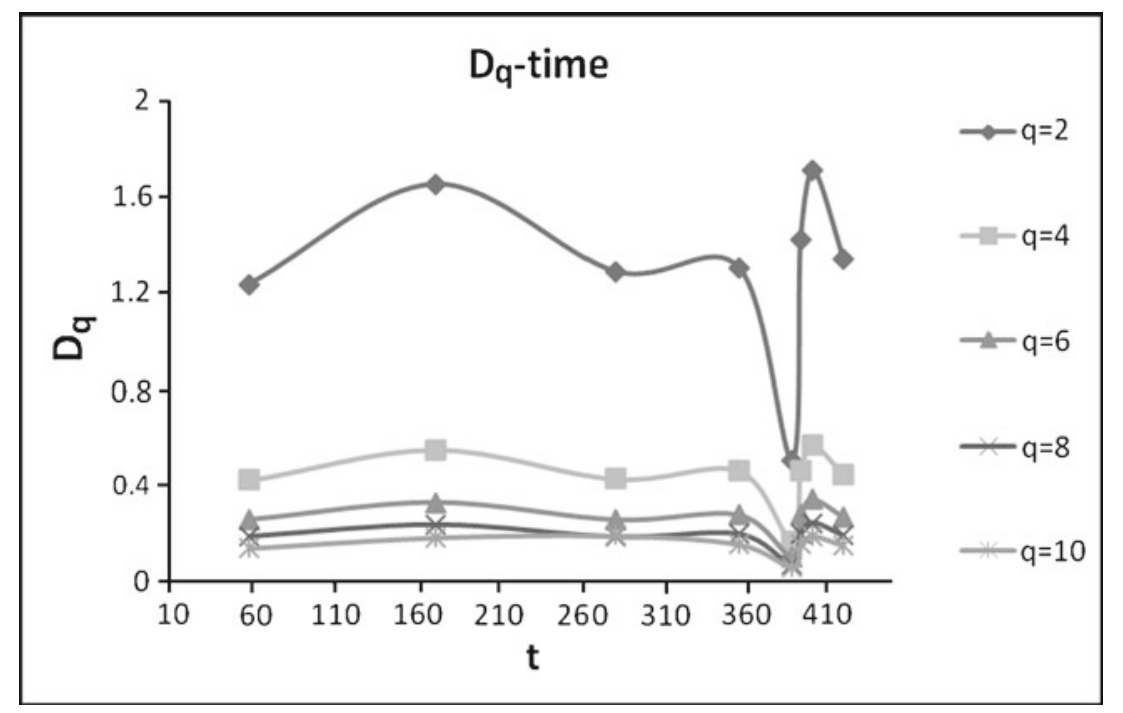

Figure 10. The temporal variation of multifractal dimension $D_{q}$ for the spatial distribution of seismic events of consecutive 100 event windows for the study region is considered.

the plot of $D_{q}-q$ or $D_{q}$ spectrum for the 100 and 50 event windows. Here the middle curve shows the $D_{q}$ spectrum for the 100 events window and other two for the 50 events window. The plot demonstrates that we may characterize the spatial distribution of events as a multifractal or heterogeneous fractal. The multifractal nature suggests that the events are distributed in clusters. It also indicates a seismogenic structure which can include several interconnected structures of complex Himalayan thrust systems. Further, $D_{2}-D_{22}$ variation with time for the 50 and 100 event windows are listed in tables 1 and 2, respectively as well as depicted in figure 9 . They show similar pattern as in the variation of $D_{C}$ versus time.

Variation of $D_{q}$ with time for the 100 events window distribution which is shown in figure 10 and it clearly indicates that $D_{q}$ fluctuates between 0.50 and 1.71 in time. The variation of $D_{q}$ for all the $q$ values with respect to time has similar nature like earlier $D_{q}$ and $D_{C}$ plots. The decrease and then the increase of $D_{q}$ with respect to the spatial distribution of seismic events indicate clustering and diffuse seismicity in a multifractal structure, respectively. The temporal variation of $D_{q}$ reflects the accumulation and release of strain energy within the tectonic stress field (Roy and Nath 2007).

\section{Discussion}

Tectonic processes generally activate the fault system and the strain accumulation results in highly stressed zones. The rupture may then nucleate from those stressed zones accounting for most of the earthquakes (figure 5a and b). The stressed zones control the distribution of scores of intermediate size earthquakes over a fault zone and modulated by fault surface heterogeneities. These zones interestingly possess different physical states and properties and are difficult to map by various geophysical techniques available. Imaging this intriguing nature of the sub-elements of the megathrusts is a challenge to be overcome by earth scientists.

The stress pattern in this region, therefore, appears to be a resultant of the complex interplay of the tectonic zone with respect to the Indian shield in the south. The occurrence of earthquakes in the Kumaun Himalaya and its surrounding regions are governed by the stress accumulation and strain release pattern that depends on the Indian plate motion along the Himalayan arc and the complex variation of crustal structure in the vicinity.

To start with, the correlation-dimension was calculated with the correlation integral and it indicated how the past events are correlated with each other. In other words, it can be said that correlation integral approach is a statistical tool, which helps to understand the interplay of major events in the heterogeneous crust. The correlation dimension derived from the above approach reveals the seismic clustering within the subdivisions of the study. Short-term clustering is an obvious feature of shallow seismicity, whereas long-term clustering is related to deeper seismicity.

In the study of Kumaun Himalayan region and its surroundings, the $D_{C}$ value fluctuates between 0.285 and 1.824 for 50 event windows and it varies between 0.529 and 1.661 for 100 event windows. The decrease in $D_{C}$ values indicates zones of highly 
clustered seismicity and can be considered as an indicator for a future strong event (Main 1992; Sammonds et al. 1992; Roy and Nath 2007; Roy and Mondal 2010). The significant low $D_{C}$ value patches along with the clustered pattern as shown in figure 5( $\mathrm{a}$ and $\mathrm{b})$ represents the possible rupture nucleation points of the highly stressed region. According to Bilham and Ambraseys (2005), the central gap is inferred to have developed $9 \mathrm{~m}$ of slip, comparable to the slip inferred to have occurred in 1505 earthquake. Hence they did not exclude the possibility that an elapsed period of 500 years may represent all, or a substantial portion, of the earthquake cycle in the western Nepal and Kumaun. Figure 5(c) depicts significant earthquakes between 1500 and 1950 plotted on a Cartesian projection (top) and on an oblique Mercator projection (below) centered on the pole that defines a $1695 \mathrm{~km}$ small circle fit to the edge of the Tibetan plateau. Dark shading indicates elevations $>3500 \mathrm{~m}$, and light shading indicates elevations $<100 \mathrm{~m}$. The white area between the two areas (dashed lines) indicates the width of the locked plate boundary (Bilham and Ambraseys 2005). Figure 5(d) shows the estimates for the rupture areas of earthquakes between 1500 and 1934 in the central Himalayas. White circles indicate reports that permit an intensity assessment for the 1505 earthquake (Ambraseys and Jackson 2003). Grey circles indicate reports for which no intensity can be assigned. Although a recurrence of the 1505 earthquake is considered timely (the central gap identified by Khattri 1992), re-rupture of the 1400 region would also not be unexpected (Bilham and Wallace 2005). The two boxes indicate the lowest $D_{C}$ patches in our study area. The lowest $D_{C}$ patches from the study signifies the possible highly stressed zone as shown in figure $5(\mathrm{a}$ and $\mathrm{d})$. The statistical error is depicted in tables 4 and 5 .

Multifractal study with the correlation integral approach helps to quantify the spatial distribution with the help of generalized fractal dimension. The multifractal dimension derived from the above approach points to the seismic clustering that exists within the subdivisions of the study region. Analysis reveals significant variation in the multifractal properties of seismicity between the tectonic subdivisions of the area under study. Figure 9 illustrates difference between $D_{2}$ and $D_{22}$ and is related to differences in the tendency for seismicity to be clustered or dispersed at different scales. Hence the differences between the multifractal dimension $D_{2}$ and $D_{22}$ are interpreted to result from fractal heterogeneity between regional and local scales, respectively (Öncel and Wilson 2006). Changes between the fractal dimension $D_{C}$ or $D_{2}$ and multifractal $(q=3-22)$ measures
Table 4. Error in each window of consecutive 50 event windows with $D_{C}$ and $R^{2}$ values for the entire study region.

\begin{tabular}{lccc}
\hline $\begin{array}{l}\text { Serial } \\
\text { no. }\end{array}$ & $\begin{array}{r}D_{C}(\text { correlation } \\
\text { dimension })\end{array}$ & $\begin{array}{c}R^{2} \text { (correlation } \\
\text { coefficient })\end{array}$ & Error \\
\hline 1 & 1.615 & 0.989 & \pm 0.011 \\
2 & 1.522 & 0.997 & \pm 0.003 \\
3 & 1.824 & 0.994 & \pm 0.006 \\
4 & 1.431 & 0.997 & \pm 0.003 \\
5 & 1.546 & 0.997 & \pm 0.003 \\
6 & 0.836 & 0.996 & \pm 0.004 \\
7 & 1.295 & 0.997 & \pm 0.003 \\
8 & 1.280 & 0.997 & \pm 0.003 \\
9 & 0.946 & 0.997 & \pm 0.003 \\
10 & 0.285 & 0.986 & \pm 0.014 \\
11 & 1.346 & 0.995 & \pm 0.005 \\
12 & 1.253 & 0.993 & \pm 0.007 \\
13 & 1.263 & 0.994 & \pm 0.006 \\
14 & 1.579 & 0.995 & \pm 0.005 \\
15 & 1.447 & 0.994 & \pm 0.006 \\
16 & 1.192 & 0.988 & \pm 0.012 \\
\hline
\end{tabular}

Table 5. Error in each window of consecutive 100 event windows with $D_{C}$ and $R^{2}$ values for the entire study region.

\begin{tabular}{lccc}
\hline $\begin{array}{l}\text { Serial } \\
\text { no. }\end{array}$ & $\begin{array}{c}D_{C}(\text { correlation } \\
\text { dimension })\end{array}$ & $\begin{array}{c}R^{2} \text { (correlation } \\
\text { coefficient) }\end{array}$ & Error \\
\hline 1 & 1.468 & 0.991 & \pm 0.009 \\
2 & 1.661 & 0.998 & \pm 0.002 \\
3 & 1.252 & 0.999 & \pm 0.001 \\
4 & 1.363 & 0.998 & \pm 0.002 \\
5 & 0.529 & 0.989 & \pm 0.011 \\
6 & 1.371 & 0.991 & \pm 0.009 \\
7 & 1.417 & 0.996 & \pm 0.004 \\
8 & 1.506 & 0.999 & \pm 0.001 \\
\hline
\end{tabular}

illustrate the sensitivity of the multifractal characterization to changes in the local complexity. The large difference between $D_{2}$ and $D_{22}$ suggests the presence of significant 'fractal heterogeneity' within the epicentre distribution of shallow seismicity due to differences in fault complexity at local scales. With the help of multifractal measures, the fractal properties of complex fault system is more suitably characterized as shown in figure 9 .

Regions of low values of $D_{2}$ and $D_{22}$ indicate the clustering of events. $D_{q}$ also show very low values, which vary with time. Sudden decrease in the $D_{q}$ value may indicate release of a large amount of strain energy accumulated at the stressed region (Roy and Nath 2007; Roy and Padhi 2007). Further increase of $D_{q}$ value shows declustering of events or diffused seismicity before the large earthquake event indicated in figure 9.

The combined observational and data analysis evidence suggest that the period of increased 
moment release in moderate earthquakes signal the establishment of long wavelength correlations in the regional stress field (Jaume and Sykes 1999). The central hypothesis in the critical point model for regional seismicity is that it is only during these time periods that a region of the earth's crust is truly in or near a 'self-organized critical' (SOC) state (Ito and Matsuzaki 1990), such that small earthquakes cascade into much larger events. This may be attributed to self similarity of earthquakes of different scales, which may allow fractures to self-organize in order to attain criticality as detected by the clustering of events at or in the immediate vicinity of the zone of stress accumulation ultimately causing the main shock. These clusterings can be monitored by the correlation integral technique by considering well-constrained earthquake catalogue of seismically active regions of the world. Sornette and Sammis (1995); Sammis et al. (1996); Saleur et al. (1996a, 1996b) and Sammis and Smith (1999) also argue that the observed power-law build-up of intermediate events before a great earthquake represent the approach of the appropriate region towards a state of SOC. Thus, the low $D_{C}$ may be an indication of SOC, which corresponds to a power-law build-up, and is a warning of a possible strong earthquake for the Kumaun Himalaya and its surroundings (Singh et al. 2010). Table 3 gives a close comparison of $D_{C}$ and b-values from frequency magnitude (Guttenberg-Richter) relationship. A sudden-drop of fractal dimension provides a quantitative measure of the damage localization (or the clustering degree of microcracks/voids), and it might be viewed as a likely precursor prior to a final catastrophic failure (Sammonds et al. 1992; Lu et al. 2005). And the decrease of fractal dimension corresponds to a reduction of b-value, which has also been suggested as a possible precursor to predict earthquakes ( $\mathrm{Lu}$ et al. 2005). However, it should be noted that, more physical details on the reduction of fractal dimension or b-value, especially at critical failure, are needed for a reliable prediction.

Thus, in order to study the presence of high seismic regime, the favourable condition for the release of accumulated stress and accelerating seismic activity of moderate-sized earthquakes, may be assessed through a precursory spatio-temporal $D_{C}$ variation study. Kagan $(1994,1997,1999)$ and Main $(1995,1996)$ discuss the advances in statistical analysis of seismological data, and the new understanding of the scaling properties of seismicity, including possible universality of major properties of earthquake occurrence. They conclude that these techniques provide a unique opportunity to evaluate seismic hazard and to estimate the short-term and long-term rate of future earthquake occurrence, i.e., to forecast earthquake statistically.
In western Nepal (between longitudes $80.5^{\circ}$ and $82.5^{\circ} \mathrm{E}$ ) a cluster is oriented $118^{\circ} \mathrm{NE}$. and the cluster is elongated and nearly in horizontal plane. These clusters are interpreted to reflect stress build-up in the interseismic period (Pandey et al. 1995; Bilham et al. 1997; Cattin and Avouac 2000) with aseismic creep being located beneath the Higher Himalayas. The recent clustering indicated in figure $5(\mathrm{a}$ and $\mathrm{b})$ supports the earlier finding. It may thus be inferred that these clusters following the southern boundary of the Higher Himalayas of Nepal, mark the tip of aseismic slip zone beneath the Higher Himalayas and southern Tibet, and that the transition from the aseismic creep dislocation zone to the locked zone does not occur in the same context in western Nepal, it is located along a gently dipping segment of the MHT.

\section{Conclusion}

What is significant in our finding is that a sudden drop in $D_{C}$ value along with b-value is observed in the year 2005. The sudden decrease of such parameters relative to one another clearly indicates the possible rock failure that may occur near the time of a strong earthquake. Whatever the fractal structure of the seismicity, a lower fractal dimension is generally produced due to an increased clustering. Here the low $D_{C}$ patches as obtained from clustering pattern shown in figure 5(a) is an indicator of a highly stressed region. Further, multifractal study lead us to understand the spectra of fractal dimension, i.e., the change of fractal dimension with different $q$ values for the earthquake distribution in the study area. The drastic change of $D_{q}$ is observed for the $q=2, \ldots, 12$ (figure 8) where we see the cluster within cluster pattern indicating heterogeneity of the crust. The $D_{2}-D_{22}$ versus time shows the analogous trend of clustering of earthquakes with a multifractal component. Our analysis gives us hazard indicators. An impending strong earthquake with magnitude of $6.5 \mathrm{M}$ and higher may dissipate a sufficient proportion of the accumulated regional strain to destroy these long wavelength stress correlations and bring the region out of a SOC state. Thus, this numerical parameter indicates an impending strong future earthquake which may help in better hazard mitigation and, therefore, disaster management for the Kumaun Himalaya and its surrounding region.

\section{Acknowledgements}

The authors gratefully acknowledge Ministry of Earth Science, Government of India for sponsoring this work (Project MoES/P.O.(Seismo)/ 
GPS/60/2006). Wadia Institute of Himalayan Geology is thankfully acknowledged for providing local network data. They are also thankful to anonymous reviewer and Prof. Malay Mukul, Associate Editor for suggestions that improved the manuscript.

\section{References}

Aki K 1981 A probabilistic synthesis of precursory phenomena earthquake prediction; Maurice Ewing Ser. Am. Geophys. Union. Washington 4 556-574.

Aki K 1984 Asperities, barriers, characteristic earthquakes and strong motion prediction; J. Geophys. Res. 89 58675872 .

Ambraseys N and Jackson D 2003 A note on early earthquakes in the northern and southern Tibet; Curr. Sci. 84 $571-582$.

Beck S L and Ruff L J 1984 The rupture process of the great 1979 Colombia earthquake: Evidence for an asperity model; J. Geophys. Res. 89(B-11) 9281-9291.

Bilham R 1995 Location and magnitude of the 1833 Nepal earthquake and its relation to the rupture zones of contiguous great Himalayan earthquakes; Curr. Sci. 69(2) $155-187$.

Bilham R, Bodin P and Jackson M 1995 Entertaining a great earthquake in western Nepal: Historic inactivity and development of strain; J. Nepal Geol. Soc. 11 73-88.

Bilham R, Larson K, Freymueller J and Idylhim members 1997 GPS measurements of present-day convergence across the Nepal Himalaya; Nature 386 1-94.

Bilham R and Ambraseys N 2005 Apparent Himalayan slip deficit from the summation of seismic moments for Himalayan earthquakes, 1500-2000; Curr. Sci. 88(10) 1658-1663.

Bilham R and Wallace K 2005 Future $M_{w}>8$ earthquakes in the Himalaya: Implications from the 26 December 2004 $M_{w}=9.0$ earthquake on India's eastern plate margin; Geol. Surv. India Spec. Publ. 85 1-14.

Bunde A, Havlin S and Roman H E 1990 Multifractal features of random walks on random fractals; Phys. Rev. A 42 6274-6277.

Cattin R and Avouac J P 2000 Modeling mountain building and the seismic cycle in the Himalaya of Nepal; $J$. Geophys. Res. Solid Earth. 105(6) 13,389-13,407.

Feng Xia-Ting and Seto Masahiro 1999 Fractal structure of the time distribution of microfracturing in rocks; Geophys. J. Int. 136 275-285.

Gansser A 1964 Geology of Himalayas; Interscience Publishers, London.

Gahalaut V K and Chander R 1997 Evidence for an earthquake cycle in the NW outer Himalayas near $78^{\circ}$ longitude, from precision levelling observation; Geophys. Res. Lett. 24 225-228.

Grassberger P and Procaccia I 1983 Characterizations of stranger attractors; Phys. Rev. Lett. 50 346-349.

Halsey T C, Jenson M H, Kadanoff L P, Procaccia I and Shraiman B I 1986 Fractal measure and their singularities: The characterization of strange sets; Phys. Rev. A 33(2) 1141-1151.

Hilarov V L 1998 Self-similar crack-generation effects in the fracture process in brittle materials; Modelling Simul. Mater. Sci. Eng. 6 337-342.

Hirata T and Imoto M 1991 Multifractal analysis of spatial distributions of microearthquake in the Kanto Region; Geophys. J. Int. 107 155-162.
Ito K and Matsuzaki M 1990 Earthquakes as self-organized critical phenomena; J. Geophys. Res. 95 6853-6860.

Jaume S C and Sykes L R 1999 Evolving towards a critical point: A review of accelerating seismic moment/energy release prior to large and great earthquakes; Pure Appl. Geophys. 155 279-306.

Jouanne F, Mugnier J L, Gamond J F, Le Fort P, Pandey M R, Bollinger L, Flouzat M and Avouac J P 2004 Current shortening across the Himalayas of Nepal; Geophys. J. Int. 157(1) 1-14.

Kagan Y Y 1994 Observational evidence for earthquakes as a nonlinear dynamic process; Physica D 77 160-192.

Kagan Y Y 1997 Are earthquake predictable? Geophys. J. Int. 131 505-525.

Kagan Y Y 1999 Is earthquake seismology a hard, quantitative science? Pure Appl. Geophys. 155 233-258.

Khattri K N 1987 Great earthquakes, seismicity gaps and potential for earthquake disaster along Himalaya plate boundary; In: Earthquake Prediction (eds) K Mogi and K N Khattri, Tectonophys. 138 79-92.

Khattri K N 1992 Seismic hazard in Indian region; Curr. Sci. 62 109-116.

Khattri K N and Tyagi A R 1983a Seismicity patterns in the Himalayan plate boundary and identification of the areas of high seismic potential; Tectonophys. 96(3/4) 281-297.

Khattri K N and Tyagi A R 1983b The transverse tectonic features in Himalaya; Tectonophys. 96(1/2) 19-29.

King G 1983 The accommodation of large strains in the upper lithosphere of the earth and other solids by selfsimilar fault system: The geometrical origin of b-value; Pure Appl. Geophys. 121 761-815.

Legrand D, Cisternas A and Dorbath L 1996 Multifractal analysis of the 1992 Erzincan aftershock sequence; Geophys. Res. Lett. 23(9) 933-936.

Lu C, Mai Y-W and Xie H 2005 A sudden drop of fractal dimension: A likely precursor of catastrophic failure in disordered media; Philosophical Magazine Lett. 85(1) 33-40.

Main I G 1992 Damage mechanics with long-range interactions - correlation between the seismic b-value and the fractal 2-point correlation dimension; Geophys. J. Int. $111531-541$.

Main I G 1995 Earthquake as critical phenomena implication for probabilistic seismic hazard analysis; Bull. Seismol. Soc. Am. 85 1299-1308.

Main I G 1996 Statistical physics. Seismogenesis and seismic hazard; Rev. Geophys. 34 433-462.

Mandal P, Mabawonku A O and Dimri V P 2005 Selforganized fractal seismicity of reservoir triggered earthquakes in the Koyna-Warna seismic zone, western India; Pure Appl. Geophys. 162 73-90.

Mandelbrot B B 1989 Multifractal measures: Especially for the Geophysicist; Pure Appl. Geophys. 131(1/2) 5-42.

Molnar P 1987 The distribution of intensity associated with the 1905 Kangra earthquake and bounds of the extent of the rupture zone; J. Geol. Soc. India 29 211-229.

Molnar P and Pandey M R 1989 Rupture zones of great earthquakes in the Himalayan region; In: Frontiers of Seismology in India (ed.) Brune J N, Proc. Indian Acad. Sci. 98 61-70.

Nakaya S and Hashimoto T 2002 Temporal variation of multifractal properties of seismicity in the region affected by the mainshock of the October 6, 2000 Western Tottori prefacture, Japan, earthquake $(M=7.3)$; Geophys. Res. Lett. 29 133-1-133-4.

Öncel A O, Main I, Alptekin O and Cowie 1996 Spatial variation of the fractal properties of seismicity in the Anatolian fault zones; Tectonophys. 257 189-202. 
Öncel A O and Wilson T H 2002 Space-time correlations of seismotectonic parameters: Example from Japan and from Turkey preceding the Izmith earthquake; Bull. Seismol. Soc. Am. 92 339-349.

Öncel A O and Wilson T 2004 Correlation of seismotectonic variables and GPS strain measurements in western Turkey; J. Geophys. Res. 109 B11306.

Öncel A O and Wilson T 2006 Evaluation of earthquake potential along the northern Anatolian fault zone in the Marmara sea using comparisons of GPS strain and seismotectonics parameters; Tectonophys. 418 205-218.

Pandey M R, Tandukar R P, Avouac J P, Lave J and Massot J P 1995 Evidence for recent interseismic strain accumulation on a mid-crustal ramp in the central Himalayas of Nepal; Geophys. Res. Lett. 22 751-758.

Pawelzik K and Schuster H G 1987 Generalized dimensions and entropies from a measured time series; Phys. Rev. 35 481-484.

Roy P N S and Ram A 2006 A correlation integral approach to the study of 26 January 2001 Bhuj earthquake. Gujarat, India; J. Geodyn. 41 385-399.

Roy P N S and Padhi Ami 2007 Multifractal analysis of earthquakes in the southeastern Iran-Bam region; Pure Appl. Geophys. 167 2271-2290.

Roy P N S and Nath S K 2007 Precursory correlation dimensions for three great earthquakes; Curr. Sci. 93(11) 1522-1529.

Roy P N S and Mondal S K 2010 Identification of seismicity pattern for some destructive earthquakes; In: Proceedings of the AGU Chapman Conference on Complexity and Extreme Events in Geosciences, National Geophysical Research Institute, Hyderabad, India, 57p.

Rundle J B, Kanamori H and McNally K C 1984 An inhomogeneous fault model for gaps asperities, barriers and seismicity migration; J. Geophys. Res. 89 10,219-10,231.

Saleur H, Sammis C G and Sornette D 1996a Discrete scale invariance, complex fractal dimensions, and log-periodic fluctuations in seismicity; J. Geophys. Res. 101 17,66117,677 .
Saleur H, Sammis C G and Sornette D 1996b Renormalization group theory of earthquakes; Nonlinear Process. Geophys. 3 102-109.

Sammis C G and Smith S W 1999 Seismic cycles and the evolution of stress correlation in cellular automation models of finite fault network; Pure Appl. Geophys. 155 307-334.

Sammis C G, Sornette D and Saleur H 1996 Complexity and earthquake forecasting, reduction and predictability of natural disasters, SFI studies in the science of complexity; vol. XXV (eds) Rundle J B, Klein W and Turcotte DL (Reading, Mass: Addison-Wesley); pp. 143-156.

Sammonds P R, Meredith P G and Main I G 1992 Role of pore fluid in the generation of seismic precursors to shear fracture; Nature 359 228-230.

Singh H N, Paudyal H, Shanker D, Panthi A, Kumar A and Singh V P 2010 Anomalous seismicity and earthquake forecast in western Nepal Himalaya and its adjoining Indian region; Pure. Appl. Geophys. 167 667-684.

Sornette D and Sammis C G 1995 Complex critical exponents from renormalization group theory of earthquakes: Implications of earthquake predictions; J. Phys. 22 411-414.

Teotia S S, Khattri K N and Roy P K 1997 Multifractal analysis of seismicity of the Himalyan region; Curr. Sci. 73 359-366.

Telesca L, Cuomo V, Lapenna V and Macchiato M 2001 Identifying space-time clustering properties of the 1983-1997 Irpinia-Basilicata (southern Italy) seismicity; Tectonophys. 330(1-2) 93-102.

Valdiya K S 1976 Himalayan transverse faults and folds and their parallelism with subsurface structures of north Indian plains; Tectonophys. 32 353-386.

Wright D 1877 History of Nepal; 1966 reprint: Calcutta, Ranjan Gupta, 271p.

Xie H 1992 Fractals in Rock Mechanics; A.A. Balkema, Rotterdam

USGS (html link) http://earthquake.usgs.gov/earthquakes/ eqarchives/epic/epic_rect.php 